\title{
Smoking reduction, smoking cessation, and incidence of fatal and non-fatal myocardial infarction in Denmark 1976-1998: a pooled cohort study
}

\author{
N S Godtfredsen, M Osler, J Vestbo, I Andersen, E Prescott
}

J Epidemiol Community Health 2003;57:412-416

See end of article for authors' affiliations

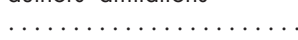

Correspondence to: Dr N S Godffredsen, Høyrups allé $28 a$ DK-2900 Hellerup, Denmark; ng@ipm.hosp.dk

Accepted for publication 30 October 2002
Objective: To analyse the effects of smoking reduction and smoking cessation on incidence of myocardial infarction after adjustment for established cardiovascular risk factors.

Design: Prospective cohort study with record linkage to mortality and hospital registers. The association of individual change in smoking with myocardial infarction was examined in Cox proportional hazard analyses with continuous heavy smokers ( $\geqslant 5$ cigarettes/day) as reference.

Setting: Pooled data from three population studies conducted in Copenhagen, Denmark.

Participants: 10956 men and 8467 women with complete information on smoking habits at two examinations five to ten years apart were followed up from the second examination for a first hospital admission or death from myocardial infarction. Mean duration of follow up was 13.8 years.

Main results: A total of 643 participants who were heavy smokers at baseline reduced their daily tobacco consumption by at least $50 \%$ without quitting between first and second examination, and 1379 participants stopped smoking. During follow up 1658 men and 521 women experienced a fatal or non-fatal myocardial infarction. After adjustment for cardiovascular risk factors, people who stopped smoking had a decreased risk of myocardial infarction, hazard ratio 0.71 (95\% confidence intervals 0.59 to 0.85$)$. Smoking reduction was not associated with reduced risk of myocardial infarction, hazard ratio 1.15 (95\% confidence intervals 0.94 to 1.40 ). These associations remained unchanged after controlling for baseline illness in different ways.

Conclusions: Smoking cessation in healthy people reduces the risk of a subsequent myocardial infarction, whereas this study provides no evidence of benefit from reduction in the amount smoked.
A lthough a decline in mortality and morbidity rates from coronary heart disease (CHD) has been observed in the past three decades in Denmark and most other Western countries, ${ }^{1}$ CHD is still the largest cause of death in those countries. $^{23}$ Acute myocardial infarction (MI) accounts for about three quarters of all fatal CHD events and half of all hospital admissions for CHD. ${ }^{3}$

Cigarette smoking is considered one of the major modifiable risk factors attributing to $\mathrm{CHD}{ }^{4}$ Smoking cessation has consistently been proved crucial in preventing fatal events and recurrent disease. ${ }^{5}$ However, results from non-pharmacological intervention studies of secondary prevention of CHD with respect to modifiable risk factors have in general been disappointing. ${ }^{6}$ Especially, long term smoking abstinence rates among patients with established CHD or prior MI, or both, are only slightly higher than corresponding rates in the general population..$^{78}$ Therefore, new strategies towards tobacco harm reduction are emerging. One such approach is smoking reduction-that is, smoking fewer cigarettes per day-which has gained increased attention. It has been suggested that heavy smokers who are unwilling or unable to quit their habit completely should be encouraged to reduce their smoking by $50 \%$ and substitute the remaining demand for nicotine with nicotine replacement therapy (NRT). ${ }^{9}$ However, evidence that this strategy benefits health, is lacking.

The main aim of this study was to examine the effects of self reported, unassisted smoking reduction and smoking cessation on incidence of fatal and non-fatal MI in a population sample by record linkage with the Danish National Board of Health for vital status and a nationwide hospital register for hospital admissions.

\section{METHODS}

\section{Participants}

The study is based on pooled data from three prospective population studies conducted in and around Copenhagen. The Copenhagen city heart study (CCHS) comprised 18039 randomly selected men and women aged 20-93 years from central Copenhagen. The Glostrup population studies (GPS), from which three birth cohorts $(1897,1914,1936)$ and the MONICA I were used, consisted of 7582 persons from Copenhagen suburbs. The Copenhagen male study (CMS) sampled 5241 men from 14 selected workplaces in Copenhagen. All studies have been described in detail previously. ${ }^{10-13}$ Initial examinations took place between 1964 and 1988 with most participants being recruited in the 1970s and re-examinations occurring at intervals of 5-10 years. The examinations included a self administered questionnaire containing health related and lifestyle related items, as well as a detailed physical examination. The mean response rate was $77 \%$, ranging from $69 \%$ to $88 \%$. Thus, our study comprises the 19423 adults (8467 women) who participated in two consecutive investigations about five years apart and who provided adequate information on smoking habits on both occasions. Participants with a register diagnosis or a self reported hospital admission for MI before enrolment $(n=216)$ were excluded from analysis. The study population is outlined in table 1 .

\section{Assessment of smoking and other cardiovascular risk} factors

Smoking status and changes in smoking habits in this study are self reported. At each examination, participants were

Abbreviations: $\mathrm{CHD}$, coronary heart disease; $\mathrm{MI}$, myocardial infarction 
Table 1 Overview of the study population (total $n=19423$ )

\begin{tabular}{|c|c|c|c|c|c|}
\hline Cohort of origin & $\begin{array}{l}\text { Year of first/second } \\
\text { examination }\end{array}$ & Men (n) & Women (n) & Age at examinations & $\begin{array}{l}\text { Myocardial infarctions } \\
\text { (n)t }\end{array}$ \\
\hline $\mathrm{CCHS}$ & $1976 / 83$ & 4718 & 6148 & 20-93 & 1183 \\
\hline GPS, 1897 cohort & $1967 / 77$ & 88 & 120 & $70-80$ & 38 \\
\hline GPS, 1914 cohort & $1964 / 74$ & 249 & 238 & $50-60$ & 80 \\
\hline GPS, 1936 cohort & $1976 / 81$ & 449 & 502 & $40-45$ & 36 \\
\hline MONICA I* & $1981 / 88$ & 1498 & 1459 & $30-65$ & 137 \\
\hline CMS & $1970 / 76$ & 3954 & - & $39-65$ & 705 \\
\hline Total & $1964-1988$ & 10956 & 8467 & 20-93 & 2179 \\
\hline
\end{tabular}

*The MONICA project is an international study conducted by the World Health Organisation to monitor trends in, and determinants of, mortality from cardiovascular disease. †Participants with a register diagnosis of myocardial infarction before enrolment $(n=216)$ were excluded.

asked whether they smoked or not, and if affirmative about amount, duration, inhalation, and preferred type of tobacco (cigarettes, cheroots, cigars, pipe, and/or mixed). Ex-smokers were asked about duration of smoking. Tobacco consumption was calculated by equating a cigarette to $1 \mathrm{~g}$ tobacco, a cheroot to $3 \mathrm{~g}$, and a cigar to $5 \mathrm{~g}$. In order to measure a substantial reduction in tobacco consumption, we defined smoking reduction as self reported smoking of $15 \mathrm{~g}$ tobacco or more at first examination and reporting a decrease of at least 50\% without quitting at the second examination. This definition of smoking reduction is similar to what is used in the clinical studies of smoking reduction. ${ }^{914}{ }^{15}$ Smoking cessation was defined as reporting active smoking at the first examination and reporting ex-smoking at the second. We therefore divided the study population into the following smoking categories: reducers, new ex-smokers (quitters), sustained neversmokers, sustained ex-smokers, sustained light smokers ( $1-14 \mathrm{~g} /$ day), and sustained heavy smokers ( $\geqslant 15 \mathrm{~g} /$ day, reference group). The few persons who did not meet the criteria for the above mentioned changes in smoking habits (for example, reduced by less than $50 \%$ or ex-smokers resuming smoking) were placed in the category to which they belonged at the second examination. Information on biochemical validation of smoking status was only available for a proportion of subjects, but measurements correlated well with self reported information of smoking cessation or smoking reduction (table 2).

We measured arterial blood pressure with participants in sedentary position after at least a rest of five minutes. Serum total and high density lipoprotein cholesterol was non-fasting in the Copenhagen city heart study but fasting in the other cohorts. Body mass index was calculated as weight $(\mathrm{kg}) /$ height $(\mathrm{m})^{2}$ and divided into following categories: $<18.5 \mathrm{~kg} / \mathrm{m}^{2}$, $18.5-24 \mathrm{~kg} / \mathrm{m}^{2}, 25-29 \mathrm{~kg} / \mathrm{m}^{2}$, and $\geqslant 30 \mathrm{~kg} / \mathrm{m}^{2}$. We classified alcohol intake into categories according to total weekly amount (one drink $=12$ g alcohol): $<1$ drink, 1-6 drinks, 7-13 drinks, 14-27 drinks, and >27 drinks. The participants were asked about physical activity in leisure time, which we then categorised as sedentary ( $<4$ hours of activity per week) or active ( $\geqslant 4$ hours per week). Physical activity during work was recorded in five categories of increasing physical strain. We divided educational level into three categories according to years of schooling: $<8$ years (completed primary school), 8-11 years, and $>11$ years. We ascertained presence of diabetes from the questionnaire (self reported). All risk factors and covariates were assessed at the second examination.

\section{Follow up}

We followed up participants from date of second investigation until 31 December 1998 for first hospital admission or death from MI using ICD-8 diagnosis code 410 and ICD-10 diagnosis code I21. We obtained diagnoses from the National Board of Health (death certificates) and the National Patient Register (hospital records). We used the main diagnosis on the death certificate or discharge, and participants with known hospital admission for MI before the beginning of follow up

Table 2 Background characteristics according to smoking status at second examination for the pooled study population

\begin{tabular}{|c|c|c|c|c|c|c|c|}
\hline Demographics & $\begin{array}{l}\text { Never } \\
\text { smokers } \\
\mathrm{n}=4014\end{array}$ & $\begin{array}{l}\text { Ex-smokers } \\
\mathrm{n}=2929\end{array}$ & $\begin{array}{l}\text { Quitters } \\
n=1379\end{array}$ & $\begin{array}{l}\text { Light smokers } \\
\mathrm{n}=3520\end{array}$ & $\begin{array}{l}\text { Reducers } \\
(50 \%) n=643\end{array}$ & $\begin{array}{l}\text { Heavy } \\
\text { smokers } \\
n=6938\end{array}$ & p Value* \\
\hline Myocardial infarctions (n) & 246 & 334 & 191 & 397 & 118 & 841 & \\
\hline Sex (\% men) & 33.6 & 65.8 & 60.6 & 46.7 & 79.0 & 67.8 & 0.001 \\
\hline Age (y) & $55.2(12.5)$ & $57.0(10.6)$ & $56.5(11.5)$ & $56.1(11.2)$ & $56.1(10.1)$ & $52.9(9.7)$ & $<0.001 \dagger$ \\
\hline Tobacco consumption (g/day) & - & - & - & $8.3(3.3)$ & $10.5(4.5)$ & $22.2(8.7)$ & $<0.001 \dagger$ \\
\hline Inhalers (\%) & - & - & - & 65.1 & 69.6 & 80.4 & $<0.001$ \\
\hline \multicolumn{8}{|l|}{ Type of tobacco smoked } \\
\hline Cigarettes only (\%) & - & - & - & 73.3 & 49.2 & 62.0 & $<0.001$ \\
\hline Cigars, cheroots, pipe or mixed (\%) & - & - & - & 26.7 & 50.8 & 38.0 & $<0.001$ \\
\hline Duration of smoking $(y)$ & - & - & $19.4(18.1)$ & $14.0(8.4)$ & $27.0(20.9)$ & $30.9(19.3)$ & $<0.001 \dagger$ \\
\hline Expired carbon monoxide (ppm) $\ddagger$ & $2.2(1.3)$ & $2.4(2.2)$ & $4.0(5.9)$ & $8.4(7.7)$ & $8.7(8.1)$ & $13.2(10.0)$ & $<0.001 \dagger$ \\
\hline Body mass index $\left(\mathrm{kg} / \mathrm{m}^{2}\right)$ & $25.6(4.2)$ & $26.2(4.3)$ & $26.1(4.1)$ & $24.6(4.0)$ & $25.2(3.8)$ & $25.2(3.9)$ & $0.89 \dagger$ \\
\hline Systolic blood pressure $(\mathrm{mm} \mathrm{Hg})$ & $136.4(22.1)$ & $138.1(22.2)$ & $137.8(23.1)$ & $134.7(21.7)$ & $133.2(22.4)$ & $131.8(21.2)$ & $0.12 \dagger$ \\
\hline Diastolic blood pressure $(\mathrm{mm} \mathrm{Hg})$ & $83.4(11.8)$ & $83.9(12.4)$ & $82.6(13.1)$ & $81.2(11.9)$ & $78.8(13.3)$ & $80.7(13.0)$ & $0.001 \dagger$ \\
\hline Plasma total cholesterol (mmol/l) & $6.08(1.24)$ & $6.16(1.19)$ & $6.10(1.24)$ & $6.08(1.18)$ & $6.19(1.24)$ & $6.09(1.16)$ & $0.08 \dagger$ \\
\hline $\mathrm{HDL}$ cholesterol (mmol/l) & $1.28(0.59)$ & $1.27(0.44)$ & $1.23(0.46)$ & $1.23(0.46)$ & $1.24(0.41)$ & $1.23(0.59)$ & $0.56 \dagger$ \\
\hline Number $(\%)$ with diabetes & $69(1.9)$ & $98(3.8)$ & $38(3.2)$ & $64(2.0)$ & $7(1.4)$ & $130(2.4)$ & 0.14 \\
\hline Number (\%) physically inactive & $783(19.6)$ & $465(16.0)$ & $263(19.3)$ & $623(17.9)$ & $122(19.4)$ & $1522(23.7)$ & 0.02 \\
\hline Number $(\%)$ with $<8$ y education & $1673(42.9)$ & $1205(44.0)$ & $577(45.5)$ & $1653(49.2)$ & $310(57.5)$ & $2898(49.3)$ & 0.001 \\
\hline $\begin{array}{l}\text { Number (\%) with alcohol consumption >27 } \\
\text { drinks/week }\end{array}$ & $124(3.2)$ & $236(8.5)$ & $110(8.5)$ & $158(4.7)$ & $64(11.6)$ & $884(14.8)$ & 0.13 \\
\hline
\end{tabular}

Results are presented as absolute values, percentages, or means with standard deviation in parentheses. * $p$ Values represent differences between the reducers and the continuous heavy smokers. †Two sample $t$ tests. All other are $\chi^{2}$ with two tailed $p$ values. $\ddagger$ Results only from the Copenhagen City Heart Study, $3^{\text {rd }}$ survey 1991-93, $n=7016$. HDL: high density level. 


\section{Key points}

- In heavy smokers who are unable or unwilling to quit smok ing, smoking fewer cigarettes per day has been suggested as a method of tobacco harm reduction.

- A single trial has indicated an improvement in established cardiovascular risk factors after eight weeks of smoking reduction, but no large scale prospective studies have so far explored this issue.

- Data from three cohort studies in Copenhagen, Denmark were used to assess the risk of a first hospital admission or death from $\mathrm{Ml}$ in participants who reduced or stopped smoking between two examinations.

- This prospective population study suggests, for the first time, that self reported smoking reduction in heavy smokers does not reduce the risk of a fatal or non-fatal cardiac event compared with continuous heavy smoking. The study confirms the beneficial effect of smoking cessation on risk of cardiovascular disease.

- More studies are needed before public or "high risk" implementation of reduced smoking as a supportive tobacco harm reduction strategy.

were excluded. The only possible loss to follow up on the diagnosis was through emigration $(<0.4 \%)$. Mean duration of follow up was 13.8 years.

\section{Statistical methods}

To account for inter-cohort methodological differences in measurements of blood pressure and laboratory tests we divided the relevant covariates into quintiles within cohorts, by sex and age. Cox proportional hazards regression models were fitted to calculate the hazard ratios ( relative risks) of the association between smoking habits and MI with sustained heavy smokers as the reference group. Age was chosen as the underlying time scale, and the model allowed for delayed entry (left censoring) - that is, participants entered analysis at their age at the second examination. ${ }^{16}$ All analyses were stratified by sex, thus assuming equal effects of coefficients for the variables of interest, but allowing baseline hazards to differ. The covariates were included as continuous after evaluation for linearity, or otherwise treated as categorical variables as described. We tested the proportional hazards assumption in two different ways: the standard graphical check based on the log of the cumulative hazard and through a formal test of proportionality based on Schoenfeld residuals. ${ }^{16}$ This revealed a violation of the proportional hazards assumption with respect to the dependent variable (the six smoking categories described above), which was then treated in the model as a time dependent variable. Consequently, estimation of the coefficients for never smokers and ex-smokers was not possible although the subjects remained in the model. We developed additional Cox models that allowed for a $33 \%$ reduction in tobacco consumption and accounted for preclinical disease, respectively. Furthermore, analyses of all coronary heart events associated to smoking were carried out. Tests of interaction between the smoking variable and the other cardiovascular risk factors were done using a likelihood ratio test. The analyses were made with Stata. ${ }^{17}$ The results are presented as hazard ratios (HR) and 95\% confidence intervals (CI).

\section{RESULTS}

Analyses were based on 10809 men and 8398 women with complete data (table 1). During follow up, 1658 men and 521 women suffered a MI, of which 654 and 198, respectively, were fatal.

Although there were no important differences between the smoking groups and mean values of diastolic and systolic blood pressure, and cholesterol level, the sustained heavy smokers generally had a more adverse cardiovascular risk profile compared with all other smoking groups (table 2). A total of 1379 participants stopped smoking between the first two examinations, and 643 baseline heavy smokers reduced by minimum $50 \%$ without quitting. If smoking reduction was extended to include all heavy smokers who reduced by at least $33 \%$ between the first two examinations 1472 participants met this criterion, mean tobacco consumption at second examination $13.3 \mathrm{~g} /$ day.

With the exception of type of tobacco smoked and physical activity during work, all cardiovascular risk factors as well as the included covariates were strongly associated with risk of MI. There was no significant interaction between the smoking variable and level of blood pressure and cholesterol. In the Cox regression analyses with increasing adjustment, smoking reduction at either a $50 \%$ or $33 \%$ level was not associated with a decreased risk of MI compared with persistent heavy smoking (table 3). Quitting smoking between the first two examinations, and sustained light smoking was associated with a

Table 3 Hazard ratios (95\% confidence intervals) of myocardial infarction by smoking status at the second examination for the total study population $(n=19423)$ and after exclusion of participants with self reported coronary heart disease at baseline $(n=18263)$. Results from Cox's proportional hazards regression analysis, with age as underlying time scale

\begin{tabular}{|c|c|c|c|c|c|c|}
\hline \multirow[b]{2}{*}{ Smoking habits } & \multicolumn{2}{|l|}{ Unadjusted* } & \multicolumn{2}{|c|}{$\begin{array}{l}\text { Adjusted for cardiovascular risk } \\
\text { factors } \dagger\end{array}$} & \multicolumn{2}{|c|}{ Fully adjusted modelf } \\
\hline & Total population & $\begin{array}{l}\text { Self reported CHD } \\
\text { at baseline } \\
\text { excluded }\end{array}$ & Total population & $\begin{array}{l}\text { Self reported CHD } \\
\text { at baseline } \\
\text { excluded }\end{array}$ & Total population & $\begin{array}{l}\text { Self reported CHD } \\
\text { at baseline } \\
\text { excluded }\end{array}$ \\
\hline \multicolumn{7}{|l|}{ Smoking category } \\
\hline Heavy smokers & 1 & 1 & 1 & 1 & 1 & 1 \\
\hline Quitters & $\begin{array}{l}0.71 \\
(0.59 \text { to } 0.85)\end{array}$ & $\begin{array}{l}0.68 \\
(0.55 \text { to } 0.83)\end{array}$ & $\begin{array}{l}0.71 \\
(0.59 \text { to } 0.85)\end{array}$ & $\begin{array}{l}0.67 \\
(0.55 \text { to } 0.83)\end{array}$ & $\begin{array}{l}0.82 \\
(0.64 \text { to } 1.03)\end{array}$ & $\begin{array}{l}0.85 \\
(0.66 \text { to } 1.09)\end{array}$ \\
\hline Light smokers & $\begin{array}{l}0.85 \\
(0.75 \text { to } 0.97)\end{array}$ & $\begin{array}{l}0.80 \\
(0.70 \text { to } 0.92)\end{array}$ & $\begin{array}{l}0.86 \\
(0.76 \text { to } 0.98)\end{array}$ & $\begin{array}{l}0.81 \\
(0.70 \text { to } 0.93)\end{array}$ & $\begin{array}{l}0.87 \\
(0.75 \text { to } 1.00)\end{array}$ & $\begin{array}{l}0.83 \\
(0.71 \text { to } 0.94)\end{array}$ \\
\hline Reducers $(50 \%)$ & $\begin{array}{l}1.14 \\
(0.93 \text { to } 1.40)\end{array}$ & $\begin{array}{l}1.05 \\
(0.84 \text { to } 1.31)\end{array}$ & $\begin{array}{l}1.15 \\
(0.94 \text { to } 1.40)\end{array}$ & $\begin{array}{l}1.06 \\
(0.84 \text { to } 1.32)\end{array}$ & $1.17(0.91$ to 1.50$)$ & $\begin{array}{l}1.14 \\
(0.88 \text { to } 1.48)\end{array}$ \\
\hline Reducers (33\%) & $\begin{array}{l}1.06 \\
(0.91 \text { to } 1.23)\end{array}$ & $\begin{array}{l}1.03 \\
(0.87 \text { to } 1.21)\end{array}$ & $\begin{array}{l}1.04 \\
(0.89 \text { to } 1.21)\end{array}$ & $\begin{array}{l}1.01 \\
(0.86 \text { to } 1.19)\end{array}$ & $\begin{array}{l}1.09 \\
(0.91 \text { to } 1.30)\end{array}$ & $\begin{array}{l}1.08 \\
(0.89 \text { to } 1.30)\end{array}$ \\
\hline
\end{tabular}

*Cox regression model stratified by sex and adjusted for cohort of origin. †Cox regression model, additionally controlling for diastolic and systolic blood pressure, and total and high density level cholesterol level. ‡Multivariate analysis stratified by sex and adjusted for cohort, diastolic and systolic blood pressure (quintiles), total and high density level cholesterol (quintiles), body mass index (in four categories), education (in three categories), weekly alcohol consumption (in five categories), physical activity (sedentary, active), self reported diabetes (yes/no), inhalation habits (yes/no), and years as smokers (continuous). CHD, coronary heart disease. 
decreased risk of MI, hazard ratio 0.71 ( 0.59 to 0.85 ) and 0.85 (0.75 to 0.97$)$, respectively. Exclusion of participants who reported any chronic cardiac condition at baseline did not significantly change the estimates as shown in the table. Estimates remained unchanged after further adjustment for blood pressure and serum cholesterol, whereas the full model attenuated the associations of smoking cessation and light smoking with MI. We also carried out analyses that omitted events the first two to five years of follow up (not shown). This procedure did not significantly change the reported associations.

Results from Cox models with the end points being first hospital admission or death from any CHD (3215 events) are presented in table 4 . In the multivariate adjusted analyses, smoking cessation and light smoking, respectively, significantly reduced the risk of coronary heart disease by 30\% compared with continuous heavy smoking. In contrast, the hazard ratio was close to unity for reducers at both the $50 \%$ and the $33 \%$ level of reduction. These estimates were also unaltered after exclusion of baseline illness, or inserting a "time window" before analysing, or both.

\section{DISCUSSION}

In this prospective study of almost 20000 persons from Copenhagen the relative risk of MI in heavy smokers who reduced their tobacco consumption did not differ from that of heavy smokers who continued their habit unchanged.

To our knowledge, no other large studies have investigated this issue. A recent study evaluated the short-term effect of smoking reduction and cessation on cardiovascular risk factors in 33 healthy volunteers who smoked more than 14 cigarettes/day. ${ }^{18}$ After eight weeks of treatment with nasal nicotine spray, the study participants had reduced their mean tobacco consumption from $21.5 \mathrm{~g} /$ day to $10.8 \mathrm{~g} / \mathrm{day}$, and the authors found significant changes towards "healthier" levels of fibrinogen, white blood cells, and high density/low density lipoprotein ratio. The authors therefore deduced that reduced smoking might have a beneficial impact on development of cardiovascular disease.

In our study, smoking reduction is based on self report. However, in two subgroups we had measurements of expired carbon monoxide (7000 participants from the CCHS) and serum cotinine (3000 participants from the CMS), respectively. In participants who reported smoking reduction, significant lower levels of carbon monoxide and cotinine compared with continuous heavy smokers verified this. During follow up some participants who have reduced might resume heavy smoking whereas others might quit smoking altogether, thus leading to either an underestimation or overestimation of any associations. An attempt to track those who reduced by assessing smoking habits at a subsequent third examination

\section{Policy implications}

The issue of whether reducing the daily number of cigarettes in heavy smokers who are unable or unwilling to quit completely can be used as a method to reduce the health hazards associated to smoking remains unknown. Small clinical trials of short-term smoking reduction have indicated a decrease in biomarkers associated with harm from tobacco exposure. However, results from this observational study do not support that reducing tobacco exposure in itself is equal to reducing the risk of smoking induced cardiovascular disease. With the caveats that some of the lack of benefit can be attributed to compensatory smoking or underreporting, smoking reduction cannot be recommended as a harm reduction strategy unless it represents an intermediate step towards complete smoking cessation.

(available data on about $50 \%$ ) showed that about $50 \%$ continued to smoke at a reduced level, $25 \%$ had quit, and another $25 \%$ had resumed heavy smoking. This is in accordance with other studies that have neither confirmed nor disproved future cessation after smoking reduction. ${ }^{19} 20$

People who were light smokers throughout the study had about a $15 \%-20 \%$ lower risk of MI compared with heavy smokers, thus confirming the well established dose-response relation between smoking and disease. By contrast, those who reduced smoking did not seem to benefit although they did not show an adverse risk factor profile compared with the other groups. Changes in other cardiovascular risk factors other than smoking could also be of importance in this study. However, we adjusted for a wide range of possible confounders, and furthermore, our analyses of interaction between smoking and other risk factors did not show any signs of effect modification. Findings from the Münster heart study showed that smoking was associated with adverse changes in serum lipids and fibrinogen but that these changes only accounted for a small part of increased risk of CHD in smokers. ${ }^{21}$ Another recently published cohort study found equal effects of smoking on risk of cardiovascular mortality regardless of baseline serum cholesterol concentrations. ${ }^{22}$

Clearly, possible sources of unmeasured confounding or misclassification could still serve as explanations for our "null result" regarding smoking reduction. Bias attributable to misclassification of the register diagnosis of MI would only occur if it is related to changes in smoking habits, and this is unlikely. Compensatory smoking is known to play a part in smoking reduction; hence, the actual benefit of this "strategy" could be far smaller than the absolute amount of reduction. ${ }^{23}$

The lack of a beneficial effect of smoking reduction can be explained in the light of previous findings on smoking and

Table 4 Hazard ratios (95\% confidence intervals) of all coronary events by smoking status at the second examination for the total study population. Results from Cox's proportional hazards regression analysis, with age as underlying time scale

\begin{tabular}{lllll}
\hline Smoking habits & $\begin{array}{l}\text { Number of } \\
\text { events }\end{array}$ & One variable in model* & All variables in model† \\
\hline $\begin{array}{l}\text { Smoking category } \\
\text { Heavy smokers }\end{array}$ & 1208 & 1 & & 1 \\
$\quad$ Quitters & 218 & $0.65(0.56$ to 0.75$)$ & $0.68(0.53$ to 0.88$)$ \\
Light smokers & 577 & $0.75(0.68$ to 0.82$)$ & $0.71(0.63$ to 0.79$)$ \\
Reducers $(50 \%)$ & 149 & $0.99(0.84$ to 1.17$)$ & $1.02(0.83$ to 1.24$)$ \\
Reducers $(33 \%)$ & 300 & $0.95(0.84$ to 1.08$)$ & $0.99(0.86$ to 1.15$)$ \\
\hline
\end{tabular}

*Cox regression model stratified by sex and adjusted for cohort of origin. †Multivariate analysis stratified by sex and adjusted for cohort, diastolic and systolic blood pressure (quintiles), total and high density level cholesterol (quintiles), body mass index (in four categories), education (in three categories), weekly alcohol consumption (in five categories), physical activity (sedentary, active), self reported diabetes (yes/no), inhalation habits (yes/no), and years as smokers (continuous). 
CHD. Evidence suggests that the relation between smoking and morbidity and mortality from CHD depends rather on the short-term thrombogenic effects of tobacco smoke constituents on the blood vessels and not on cumulated exposure. ${ }^{24}$ Even very light smoking has recently been found to increase the incidence of MI and all cause mortality in the CCHS, ${ }^{25}$ and occasional smoking is shown to increase cardiovascular mortality among men. ${ }^{26}$ In connection with the fact that the risk of cardiovascular disease diminishes rapidly after smoking cessation, ${ }^{27}$ it could be argued that a reduction in tobacco consumption from about 20 cigarettes/day to 10 cigarettes/day is not substantial enough to detect any possible benefits with respect to the reversed dose dependent associations. In this study, smoking cessation was associated with a $30 \%$ reduction in the risk of MI when controlling for other major cardiovascular risk factors. The association was somewhat attenuated after multiple adjustments but remained statistical significant when including all CHD events. In addition, we used continuing smokers as reference group, and an element of "the healthy smoker effect" possibly weakens the association between quitting smoking and incidence of MI. This effect of smoking cessation on cardiovascular risk is in accordance with results from other large studies. ${ }^{28-30}$

In summary, data from this large prospective study suggest that smoking cessation is associated with a decreased risk of MI in people free of disease at study entrance, whereas smoking reduction in baseline heavy smokers does not imply any risk reduction. As no other larger studies have explored this issue, further investigation is needed; however at present, we recommend that reduced smoking should only be advocated as a mean of future smoking cessation.

\section{REFERENCES}

1 Osler M, Sorensen TI, Sorensen S, et al. Trends in mortality, incidence and case fatality of ischaemic heart disease in Denmark, 1982-1992. Int J Epidemiol 1996;25: 1154-61

2 McGovern PG, Pankow JS, Shahar E, et al. Recent trends in acute coronary heart disease-mortality, morbidity, medical care, and risk factors. The Minnesota Heart Survey Investigators. N Engl J Med 1996;334:884-90.

3 Tunstall-Pedoe H, Kuulasmaa K, Mahonen M, et al. Contribution of trends in survival and coronary-event rates to changes in coronary heart disease mortality: 10-year results from 37 WHO MONICA project populations. Monitoring trends and determinants in cardiovascular disease. Lancet 1999;353:1547-57.

4 Wood D. European and American recommendations for coronary heart disease prevention. Eur Heart J 1998;19 (suppl A):A12-19.

5 Wilson K, Gibson N, Willan A, et al. Effect of smoking cessation on mortality after myocardial infarction: meta-analysis of cohort studies. Arch Intern Med 2000; 160:939-44.

6 Sebregts EH, Falger PR, Bar FW. Risk factor modification through nonpharmacological interventions in patients with coronary heart disease. J Psychosom Res 2000;48:425-41.

7 Dornelas EA, Sampson RA, Gray JF, et al. A randomized controlled trial of smoking cessation counseling after myocardial infarction. Prev Med 2000;30:261-8.

8 van Berkel TF, van der Vlugt $\mathrm{W}$, Boersma $\mathrm{H}$. Characteristics of smokers and long-term changes in smoking behavior in consecutive patients with myocardial infarction. Prev Med 2000;31:732-41.
9 Bolliger CT, Zellweger J-P, Danielsson T, et al. Smoking reduction with oral nicotine inhalers: double blind, randomised clinical trial of efficacy and safety. BM 2000;321:329-33.

10 Hagerup L, Schroll M, Hollnagel H, et al. The Glostrup Population Studies. Collection of epidemiological tables. Reference values for use in cardiovascular population studies. Scand J Soc Med 1981;suppl 20:5-112.

11 Hein HO, Suadicani P, Gyntelberg F. Alcohol consumption, serum low density lipoprotein cholesterol concentration, and risk of ischaemic heart disease: six year follow up in the Copenhagen male study. BM 1996; 312:736-41.

12 Schroll M. The World Health Organization MONICA project (monitoring trends and determinants in cardiovascular disease): a major international collaboration. J Clin Epidemiol 1988;41:105-14.

13 Appleyard M, Hansen AT, Schnohr P, et al. The Copenhagen City Heart Study. A book of tables with data from the first examination (1976-78) and a 5-year follow-up (1981-83). Scand J Soc Med 1989;170:1-160.

14 Fagerström KO, Tejding R, Westin $\AA$, et al. Aiding reduction of smoking with nicotine replacement medications: hope for the recalcitrant smoker? Tobacco Control 1997;6:311-16.

15 Hurt RD, Croghan GA, Wolter TD, et al. Does smoking reduction result in reduction of biomarkers associated with harm? A pilot study using a nicotine inhaler. Nicotine Tobacco Research 2000;2:327-36.

16 Hosmer Jr DW, Lemeshow S. Applied survival analysis. New York: Wiley, 1999.

17 StataCorp. Stata statistical software: release 7.0. College Station, TX: Stata Corporation, 2001.

18 Eliasson B, Hialmarson A, Kruse E, et al. Effect of smoking reduction and cessation on cardiovascular risk factors. Nicotine Tobacco Research $2001 ; 3: 249-55$.

19 Farkas AJ. When does cigarette fading increase the likelihood of future cessation? Ann Behav Med 1999;21:71-6.

20 Hughes JR, Cummings KM, Hyland A. Ability of smokers to reduce their smoking and its association with future smoking cessation. Addiction 1999;94:109-14

21 Cullen P, Schulte H, Assmann G. Smoking, lipoproteins and coronary heart disease risk. Data from the Münster Heart Study (PROCAM). Eur Heart J 1998;19:1632-41.

22 Blanco-Cedres L, Daviglus ML, Garside DB, et al. Relation of cigarette smoking to 25-year mortality in middle-aged men with low baseline serum cholesterol. Am J Epidemiol 2002;155:354-60.

23 Benowitz NL, Jacob III P, Kozlowski LT, et al. Influence of smoking fewer cigarettes on exposure to tar, nicotine, and carbon monoxide. N Engl J Med 1986;315:1310-13.

24 Smith CJ, Fischer TH. Particulate and vapor phase constituents of cigarette mainstream smoke and risk of myocardial infarction. Atherosclerosis 2001;158:257-67.

25 Prescott E, Scharling $H$, Osler $M$, et al. Importance of light smoking and inhalation habits on risk of myocardial infarction and all cause mortality. A 22 year follow up of 12149 men and women in The Copenhagen City Heart Study. J Epidemiol Community Health 2002;56:702-6.

26 Luoto R, Uutela A, Puska P. Occasional smoking increases total and cardiovascular mortality among men. Nicotine Tobacco Research 2000; 2 : 133-9.

27 US Department of Health and Human Services. The health benefits of smoking cessation. A report of the Surgeon General, 1990. Rockville MD: Centers for Disease Control, Office on Smoking and Health, 1990. DHHS Publication No(CDC) 90-8416.

28 Keil U, Liese AD, Hense HW, et al. Classic risk factors and their impact on incident non-fatal and fatal myocardial infarction and all-cause mortality in southern Germany. Results from the MONICA Augsburg cohort study 1984-1992. Monitoring trends and determinants in cardiovascular diseases. Eur Heart J 1998;19:1197-207.

29 Stamler J, Stamler R, Neaton JD, et al. Low risk-factor profile and long-ferm cardiovascular and noncardiovascular mortality and life expectancy: findings for 5 large cohorts of young adult and middle-aged men and women. JAMA 1999;282:2012-18.

30 Tverdal A. Calculation of risk for the development of acute myocardial infarction in the normal population based on long-term follow-up studies: smokers compared with non-smokers. J Cardiovasc Risk 1999;6:287-91. 